\title{
Cell Survival Assays for Individualised Chemotherapy in Primary Glioma Cultures- Colourmetric or Luminescent?
}

\author{
Timothy P. Dawson ${ }^{{ }^{*}}$, Katherine Ashton, Aprajay Golash ${ }^{1}$, Charles H. G. Davis ${ }^{1}$, R. Venkat Iyer ${ }^{2}$, \\ Phil Roberts ${ }^{3}$, Fred Harris ${ }^{3}$, Robert W. Lea ${ }^{3}$ \\ ${ }^{1}$ Lancashire Teaching Hospitals NHS Trust, Preston, UK; ${ }^{2}$ Frenchay Hospital, Frenchay, Bristol, UK; ${ }^{3}$ University of Central Lanca- \\ shire, Preston, UK. \\ E-mail: *Timothy.Dawson@1thtr.nhs.uk
}

Received October 13 $3^{\text {th }}, 2011$; revised November $18^{\text {th }}, 2011$; accepted November $26^{\text {th }}, 2011$.

\begin{abstract}
In vitro chemosensitivity testing of short term primary glioma cultures derived from brain biopsies is still in the research phase and has not yet found a place in clinical use. The main reasons for this slow progression are the small amounts of tissue available and the lack of a suitably sensitive assay capable of use in the clinical setting. This study examines whether the MTS and ATP cell survival assays, which determine cytotoxicity via colorimetric and luminescence analysis respectively, could potentially fulfill this role. Primary glioma cultures were tested for chemosensitivity using the MTS and ATP assays and were found to be generally sensitive to cisplatin and paclitaxel but relatively resistant to carmustine and etoposide. For both assays, $L D_{50}$ values lay in the range $2-130 \mu \mathrm{g} / \mathrm{ml}$ but in the vast majority of cases, those obtained by the ATP assay were markedly lower those obtained by the MTS assay. Moreover, at cell numbers less than 2000 in the cases of paclitaxel and carmustine and less than 4500 in the case of cisplatin, these drugs were generally indicated as ineffective against the glioma cultures tested by the MTS assay but effective against these cultures by the ATP assay. These data clearly demonstrate that the ATP assay is more sensitive when estimating small cell numbers generated by primary glioma cultures from brain biopsies and more reliably detects higher kill rates by anticancer drugs. This study also supports the feasibility of using the ATP assay for chemosensitivity testing in a clinical setting.
\end{abstract}

Keywords: ATP Assay, MTS ASsay, Glioma, Primary Tumour Culture, In Vitro, Chemosensitivity Testing

\section{Introduction}

The in vitro testing of chemotherapeutic response in tumours is not a new concept but lost a great deal of momentum in the "oncogene" years of the 1970's and 1980's despite several studies which reported correlations between chemosensitivity and in vivo effect [1-4]. However such testing in gliomas remains in the research phase and has not been adopted for clinical use as has been in the case of some other cancers such as leukaemia [5-7]. The reasons for this are manifold and include: the general resistance of gliomas to chemotherapy, both in vitro and in vivo, the protective effects of the blood brain barrier, the fact that in vitro studies are performed more on established glioma cell lines and that treatment is guided by more by custom and practice than empiricism.
In addition, another highly significant factor is the relatively small amount of tumour tissue available for analysis due to the use of needle biopsy over resection for tissue diagnosis. The role of cytoreduction alone in malignant gliomas still has an uncertain role in prolonging patient survival but appears to be increasingly used as the UK follows established US practice [8-10].

Two decades ago the standard test for in vitro chemosensitivity testing was the colony forming (clonogenic) assay but the emergence of colorimetric tests greatly simplified such testing for many tumour cultures. One of the most widely used of these colorimetric tests is based on the ability of metabolically active cells to reduce the yellow tetrazolium salt of 3-(4,5-Dimethylthiazol-2-yl)-2, 5-diphenyltetrazolium bromide (MTT) to a purple product, MTT formazan. The absorbance of this compound 
can be directly related to the number of viable cells present and hence by measuring survival, the relative cytotoxic action of a drug on tumour cells [11]. However, this assay suffers from the disadvantage that MTT formazan is a crystalline precipitate that requires resolubilisation before absorbance readings can be taken. More recently, the MTT assay was modified to use the MTT analogue 3(4,5-dimethylthiazol-2-yl)-5-(3-carboxymethoxyphenyl)2-(4-sulfophenyl)-2H tetrazolium, inner salt (MTS) [12]. The MTS and MTT assays have comparable chemistry but the former assay has the advantage over the latter that its use with metabolically active cells leads to the formation of a soluble formazan compound. As with the MTT assay, the absorbance of the formazan compound produced in the MTS assay can be used to measure the number of viable cells present and the relative toxicity of drugs. Nevertheless, both the MTS and MTT assays suffer from a major disadvantage general to these colorimetric tests, since they require a significant number of cells to detect cell death and their sensitivity drops significantly at lower cell numbers. The more recently developed ATP assay, which utilises bioluminescent measurement of ATP in metabolically active cells to assess viability, has the potential to overcome this limitation [13]. Studies on cell lines and primary cultures from ovarian and gastric cancers have demonstrated that this assay is able to exhibit high sensitivity even at very low cell numbers. This has generated great interest since it now may be feasible to adopt in vitro testing to direct individualised chemotherapy treatment when there are limited amounts of tissue available [14-18].

It is known that primary glioma tumour cultures are able to yield successful short term cultures but the growth of individual tumours is still very variable and unpredictable in relation to the number of cells available for chemosensitivity testing. It is therefore important to establish that an assay used for the detection of cell survival in glioma cultures has maximal sensitivity, especially for low initial cell numbers. Recent studies have shown that the ATP assay has greater efficacy than the MTS assay in enumerating cells counts for glioma cell lines, especially in the case of very low cell numbers, and it has been suggested that the former assay may be the better choice for determining the endpoints of chemosensitivity for primary glioma cultures [19]. To investigate this suggestion, the present study compares the ability of the MTS and ATP assays to measure the susceptibility of short term cultures from malignant gliomas to a range of established anticancer drugs [20], including: cisplatin, which is an alkylating agent and has been used both alone and in combination therapy for the treatment of glioma [21]; carmustine which has been successfully incorporated into implants (Gliadel Wafer) for the treat- ment of newly diagnosed high-grade gliom a [22] 5; paclitaxel and etoposide, which have both shown efficacy in the treatment of gliomas [23-25].

\section{Material and Methods}

\subsection{Primary Culture Preparation}

The glioma tumour tissue used in this study (samples A to O) was derived from eleven patients who had undergone either stereotactic biopsy or cytoreductive surgery (age range 33 - 73 years; mean age 54 years; 7 female, 4 male; 4 secondary operations) Only tissue designated as surplus to diagnostic requirements by a consultant neuropathologist was submitted for testing. Consent was obtained from patient or consultee and the study approved by the UK, National Research Ethics Service.

Immediately upon removal, operative tissue was placed in transport medium (Dulbeco's Modified Eagle's Medium [DMEM] with penicillin [final concentration: 10,000 U/L], streptomycin [final concentration: $100 \mathrm{mg} / \mathrm{L}$ ] and amphotericin B [final concentration: $2.5 \mathrm{mg} / \mathrm{L}$ ]; all Sigma-Aldrich, UK) and transfer expedited to the laboratory. In a Class II ventilation hood, glioma samples were transferred to a dry petri dish and obvious non-tumour or necrotic material removed. Smear preparations were used to confirm the tumour nature and suitable tissue diced. Fragments were placed in a $15 \mathrm{ml}$ centrifuge tube containing $9 \mathrm{ml}$ of growth medium and $1 \mathrm{ml}$ of collagenase solution type IA (2000 digestion units $/ \mathrm{ml}$; Sigma, UK) and then incubated in a water bath at $37^{\circ} \mathrm{C}$ for 1 to $4 \mathrm{hrs}$. During incubation, the tubes were mechanically agitated every $15 \mathrm{~min}$ and the contents pipetted gently to promote disaggregation of the tumour tissue. When visual examination confirmed homogeneity, each tube was centrifuged at $300 \mathrm{~g}$ for $5 \mathrm{~min}$ and the enzyme solution discarded. The disaggregate was washed in growth medium, centrifuged and then resuspended in 10 $\mathrm{ml}$ of growth medium and transferred to a $25 \mathrm{~cm}^{2}$ cell culture flask for culture in a humidified $5 \% \mathrm{CO}_{2}$ incubator at $37^{\circ} \mathrm{C}$ (New Brunswick Scientific, UK). After 24 to $48 \mathrm{hrs}$, the medium and non-adherent material was discarded and each culture re-fed with further growth medium.

The growth medium was prepared by mixing equal volumes of DMEM and Ham's F12 medium and then adding foetal calf serum (final concentration $10 \% \mathrm{v} / \mathrm{v}$ ), streptomycin (final concentration $100 \mathrm{mg} / \mathrm{L}$ ) and penicillin (final concentration 10,000 U/L). All components of growth medium were obtained from Sigma-Aldrich (UK).

\subsection{The MTS and ATP Assays}

The MTS assay of glioma cells was performed using the CellTiter 96 assay (Promega, UK) according to the manu- 
facturer's instructions. Essentially this assay involves the addition of a single reagent, which includes MTS and phenazine ethosulfate (PES), to the cell culture under examination. In the presence of PES, MTS is reduced by reducing agents present in metabolically active cells to produce a formazan compound. The absorbance of this compound is then read at $490 \mathrm{~nm}$ and provides a measure of viable cells in the culture [12].

The ATP assay of glioma cells was performed using the CellTiter-Glo assay (Promega, UK) according to the manufacturer's instructions. Essentially this assay involves the addition of a single reagent, which includes the enzyme luciferase and its substrate, luciferin, to the cell culture under examination. The action of this reagent leads to the release of ATP from metabolically active cells whilst inactivating the ability of these cells to synthesize further ATP. In the presence of this released ATP, luciferin is oxidised by luciferase, to generate a proportional luminescent signal, which is read and provides a measure of viable cells in the culture [13].

The primary cultures were examined daily and when greater than $70 \%$ confluence was achieved (between 4 to 14 days), the cells were trypsinised by adding $1 \mathrm{ml}$ of $0.25 \%$ trypsin $(\mathrm{w} / \mathrm{v})$. After detachment, the trypsin was neutralized with an equal volume of growth medium, glioma cells thoroughly mixed by pipetting and counted in a haemocytometer. Based on these counts, cells were resuspended in an appropriate volume of medium so that $60 \mu \mathrm{l}$ aliquots of equal cell number could be added to each well of either 96 well clear plates (Nunc, UK) for MTS assay or 96 well white plates with clear bottoms (Nunc, UK) for ATP assay. Care was taken to agitate the cell suspension during aliquotting to ensure even distribution. Plates were then left in a humidified $5 \% \mathrm{CO}_{2}$ incubator at $37^{\circ} \mathrm{C}$ (New Brunswick Scientific, UK) to attach. After 24 hours, drugs in $40 \mu \mathrm{l}$ of diluent were added to plate wells to give final concentrations of: $1,2.5$, 10,25 and $100 \mu \mathrm{g} / \mathrm{ml}$ for carmustine and etoposide, 0.4 , $1,4,10$ and $40 \mu \mathrm{g} / \mathrm{ml}$ for cisplatin, and 1.36, 3.4, 13.6, 34 and $136 \mu \mathrm{g} / \mathrm{ml}$ for paclitaxel. These concentration ranges were chosen to include the published peak plasma concentrations or therapeutic dose, of each drug studied which were taken as $33 \mu \mathrm{g} / \mathrm{ml}$ for carmustine and etoposide, $4 \mu \mathrm{g} / \mathrm{ml}$ for cisplatin and $3.6 \mu \mathrm{g} / \mathrm{ml}$ for paclitaxel [26].

The plates were allowed to incubate for a further 72 hrs with drugs before reading. For the MTS assay, $20 \mu 1$ of reagent was added to each well and plates placed back in the incubator for 90 min prior to absorbance determination using a plate reader (Tecan, UK). For the ATP assay, medium was removed from each well and the plate tapped dry. $100 \mu l$ of the ATP assay reagent was then added to each well and the plate placed on a gentle shaker for 2 min followed by standing equilibration at room temperature $\left(25^{\circ} \mathrm{C}\right)$ for 15 to $30 \mathrm{~min}$. Luminescence was then measured using a plate reader (Tecan, UK). For controls, corresponding experiments were performed adding drug diluents without active chemotherapy agent and in all cases, individual well experiments were repeated fourfold.

\subsection{Data Analysis}

Absorbance and luminescence measurements were determined for drug treated and control cell populations of the glioma tumour cultures, A to O. For each replicate set, the drug concentration was plotted against absorbance or luminescence to provide a dose/response curve in MS Excel 2010 (Figure 1). The point at which the absorbance/luminescence gave $50 \%$ of the value obtained for the non-drug treated cell population was determined and extrapolated to give the drug concentration which killed $50 \%$ of the tested cell population. This drug concentration was taken as the $\mathrm{LD}_{50}$ of that drug in $\mu \mathrm{g} / \mathrm{ml}$ and was always less than, or equal to, the highest concentration of the drug used. Separate analysis of the replicate studies provided a mean and standard deviation and for each drug tested, the $\mathrm{LD}_{50}$ values were represented as bar histograms. If no drug concentration tested killed at least $50 \%$ of a cell population, that population was deemed "resistant" to that drug according to the assay and represented by a histogram bar at the maximal drug concentration used.

\section{Results}

\section{Estimation of Cell Number in Glioma Primary Tissue Cultures}

The ATP and MTS assays were used to determine the chemosensitivity of cells from glioma tissue cultures to cisplatin (15 cases), paclitaxel (13 cases), carmustine (5 cases) and etoposide (3 cases) (Figures 2-5). Drug responses exhibited by these cultures were expressed as $\mathrm{LD}_{50}$ values as measured by the ATP and MTS assay systems. In addition, data is shown relating the chemosensitivity assay results to starting cell counts of the primary glioma cultures used in the assay.

All 15 cases were tested for cisplatin sensitivity and dose-response curves were obtained for all 15 samples with the ATP assay but only 9 of these cases gave a dose-response with the MTS assay, even at the highest dose of chemotherapeutic agent. Where a dose-response curve was obtained the $\mathrm{LD}_{50}$ was calculated and those cases which showed no evidence of toxicity were deemed to be resistant and represented on the graph as bar exceeding the maximum dose used (Figure 2).

There were sufficient cells to test 13 cases with paclitaxel and all 13 gave dose-response curves with the ATP 


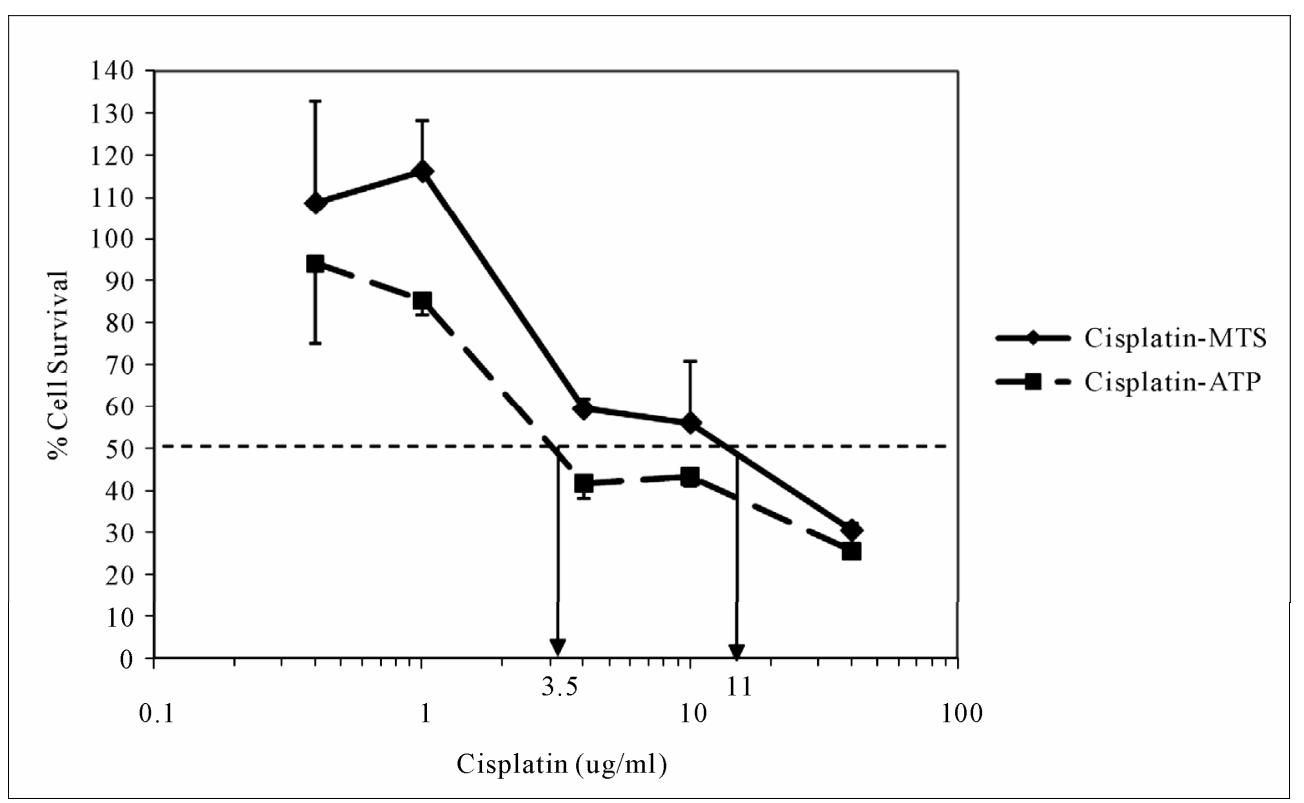

Figure 1. Typical dose response curves for primary glioma cells when treated with cisplatin. Cell survival was determined by the MTS ( $\diamond$ ) and ATP assays ( $\bullet$ ). Similar dose response curves were derived in the case of paclitaxel, carmustine and etoposide and these data used to determine $L D_{50}$ values as described in material and methods.

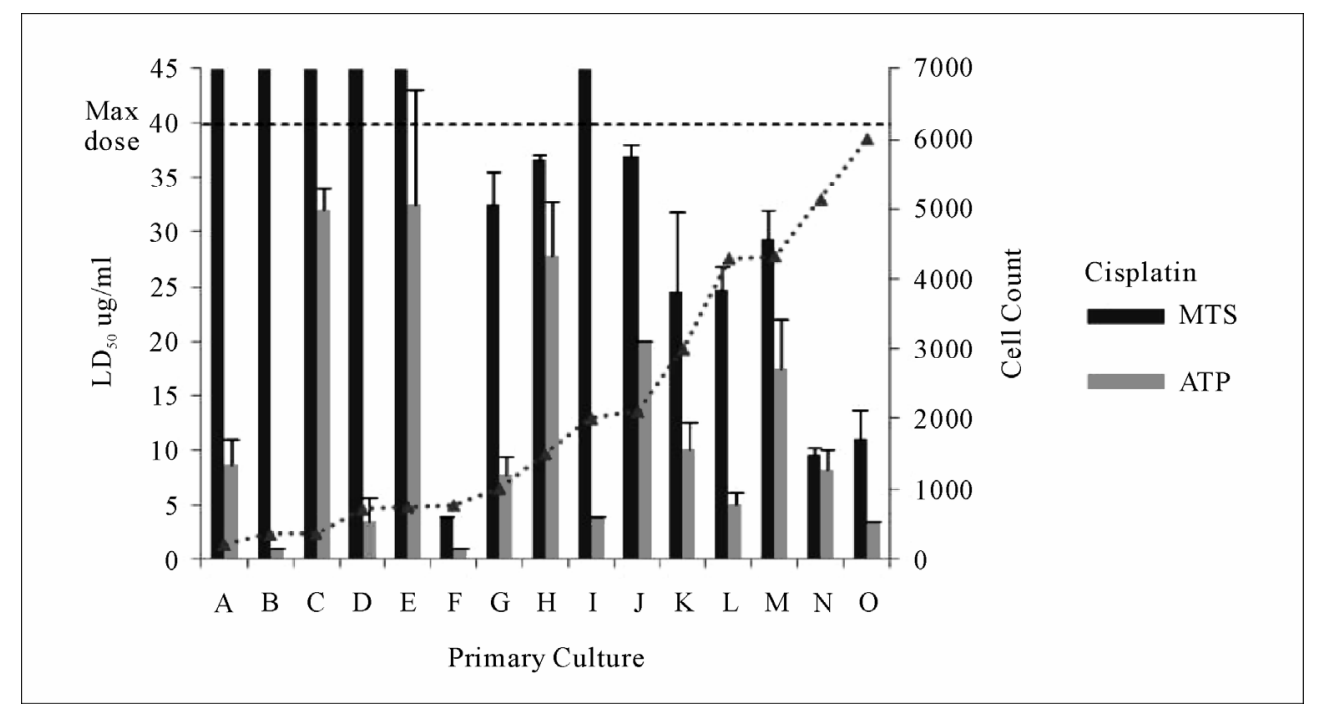

Figure 2. The responses of short term glioma tumour cultures to cisplatin using the MTS and ATP assays. It was found that the ATP assay was able to demonstrate a relationship between changes in drug concentration and the drug response of all fifteen glioma cultures that had been treated with cisplatin (glioma cultures: A to $O$ ). In contrast, MTS assay of the same cultures indicated such a relationship for nine (glioma cultures: F, G, H, J, K, L, M, N to O) whereas six (glioma cultures: A, $\mathrm{B}, \mathrm{C}, \mathrm{D}, \mathrm{E}$ and I) showed no response to cisplatin. The data are the mean of 9 replicate experiments and the error bars represent standard deviations. Where error bars go beyond the highest concentration of cisplatin (40 ug/ml), that culture was deemed resistant to the drug. In addition, data is shown relating the chemosensitivity assay results to initial cell counts of the primary glioma cultures studied.

assay but only 6 cases demonstrated a dose-response with the MTS assay. Resistance or $\mathrm{LD}_{50}$ levels were noted and are shown in Figure 3. The availability of primary glioma cell numbers limited studies on carmustine and etoposide to 5 and 3 cases respectively but these showed a similar pattern of responsiveness with the ATP and MTS assays (Figures $\mathbf{4}$ and 5).

When these responses were measured as $\mathrm{LD}_{50}$ values, for both assays, they lay in the range $1-37 \mu \mathrm{g} / \mathrm{ml}$ for cisplatin, 2 - $120 \mu \mathrm{g} / \mathrm{ml}$ for paclitaxel, $10-90 \mu \mathrm{g} / \mathrm{ml}$ for 


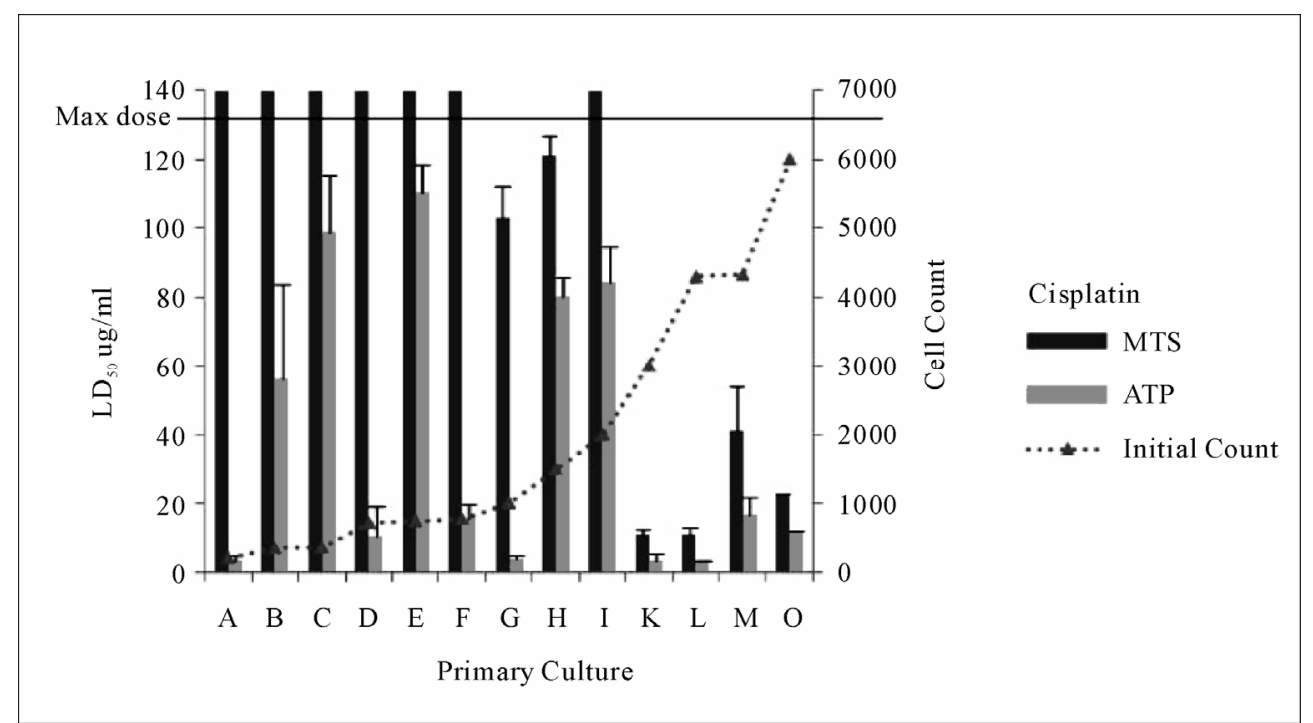

Figure 3. The responses of short term glioma tumour cultures to paclitaxel using the MTS and ATP assays. It was found that the ATP assay was able to demonstrate a relationship between changes in drug concentration and the drug response of thirteen glioma cultures that had been treated with paclitaxel (glioma cultures A to O). In contrast, MTS assay of the same cultures indicated such a relationship for six (glioma cultures; G, H, K, L, M and O) whereas seven (glioma cultures: A, B, C, D, E, F and I) showed no response to paclitaxel. The data are the mean of 9 replicate experiments and the error bars represent standard deviations. Where error bars go beyond the highest concentration of paclitaxel $(136 \mathrm{ug} / \mathrm{ml})$, that culture was deemed resistant to the drug. In addition, data is shown relating the chemosensitivity assay results to initial cell counts of the primary glioma cultures studied.

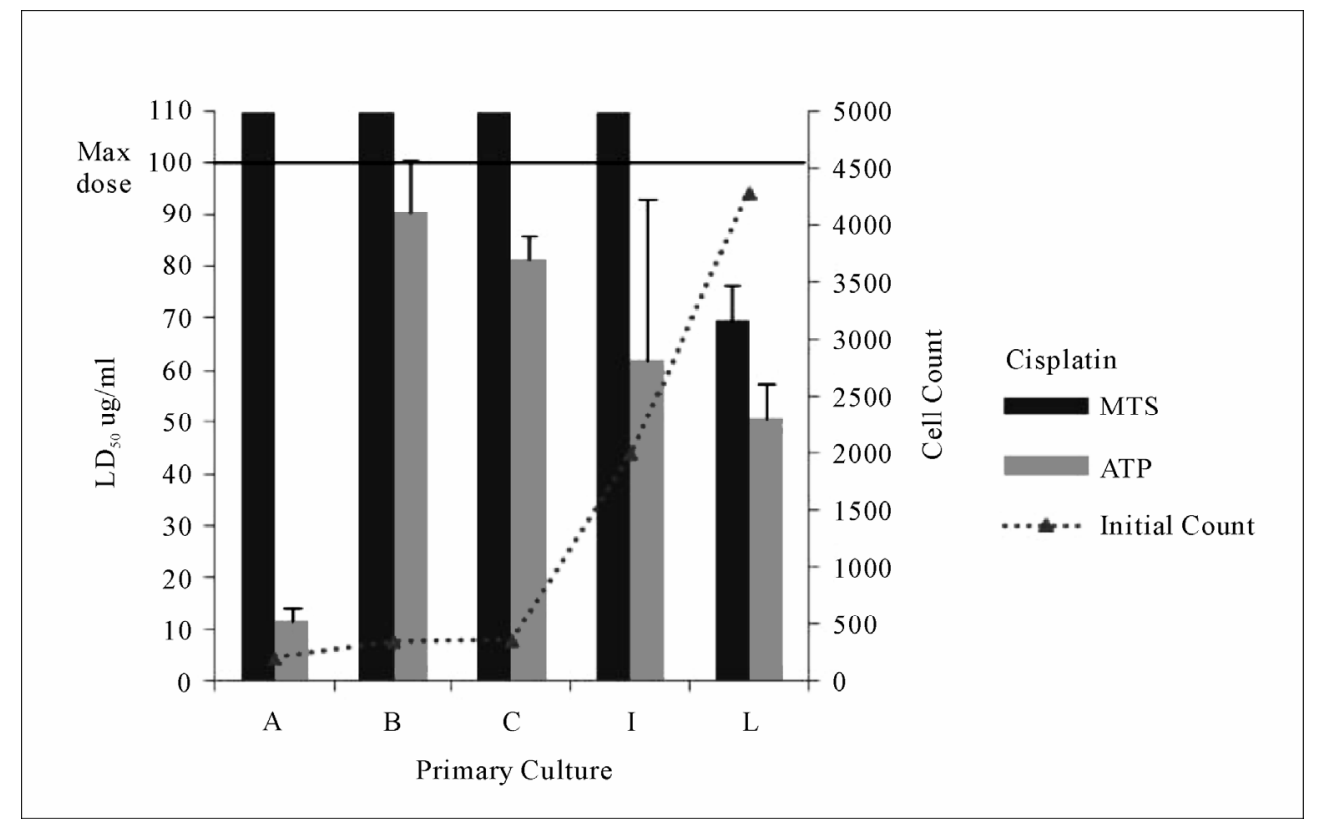

Figure 4. The responses of short term glioma tumour cultures to carmustine using the MTS and ATP assays. It was also found that the ATP assay was able to demonstrate a relationship between changes in drug concentration and the drug response of five cultures that had been treated with carmustine (glioma cultures: A, B, C, I and L). In contrast, MTS assay of the same cultures indicated such a relationship for one (glioma culture: $L$ ) whereas four (glioma cultures: A, B, C and I) showed no response to carmustine. The data are the mean of 9 replicate experiments and the error bars represent standard deviations. Where error bars go beyond the highest concentration of carmustine $(100 \mathrm{ug} / \mathrm{ml})$, that culture was deemed resistant to the drug. In addition, data is shown relating the chemosensitivity assay results to initial cell counts of the primary glioma cultures studied. In addition, data is shown relating the chemosensitivity assay results to initial cell counts of the primary glioma cultures studied. 


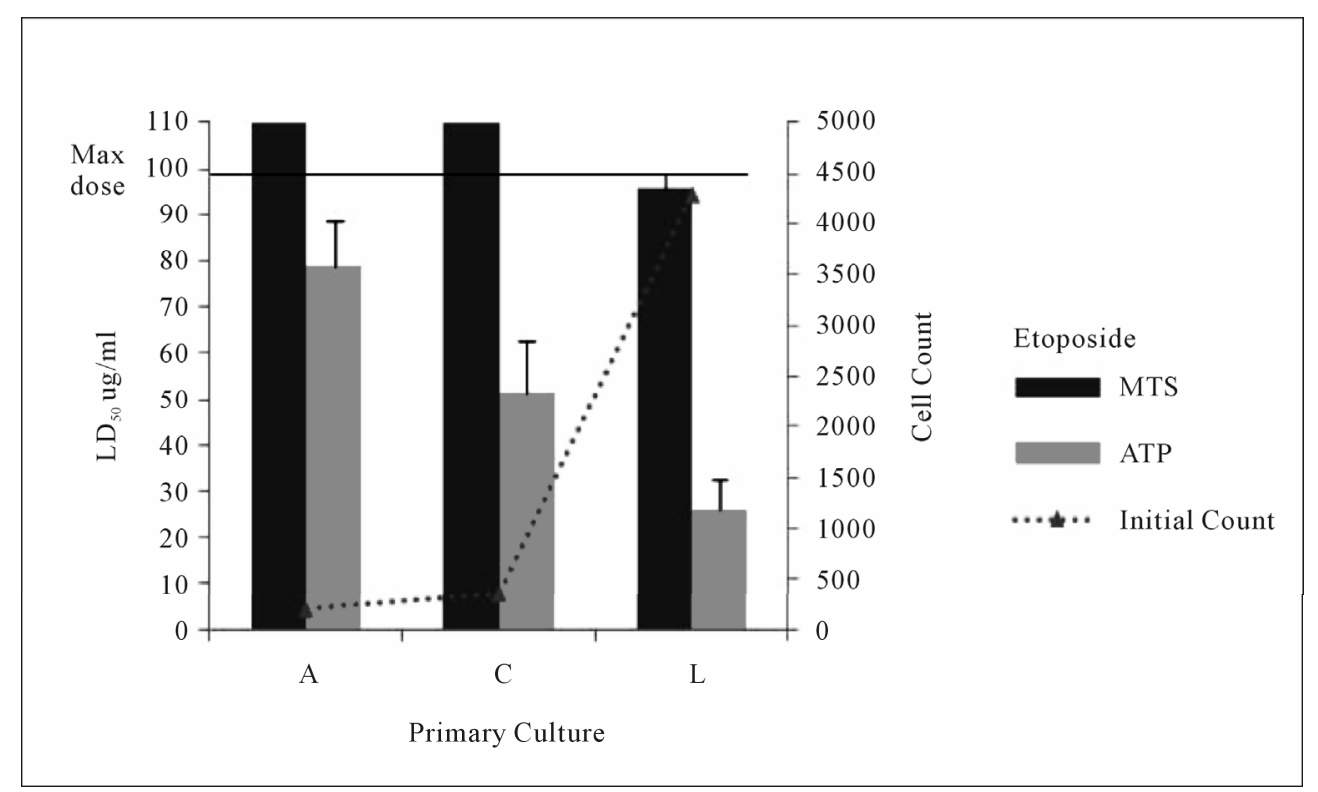

Figure 5. The responses of short term glioma tumour cultures to etoposide using the MTS and ATP assays. It was also found that the ATP assay was able to demonstrate a relationship between changes in drug concentration and the drug response of three cultures that had been treated with epotoside (glioma cultures: A, C and L). In contrast, MTS assay of the same cultures indicated such a response for only glioma culture $L$ with glioma cultures: $A$ and $C$ showing no response to etoposide. The data are the mean of 9 replicate experiments and the error bars represent standard deviations. Where there error bars go beyond the highest concentration of epotoside $(100 \mathrm{ug} / \mathrm{ml})$, that culture was deemed resistant to the drug. In addition, data is shown relating the chemosensitivity assay results to initial cell counts of the primary glioma cultures studied.

carmustine and $25-95 \mu \mathrm{g} / \mathrm{ml}$ for etoposide. However, reflecting the trend observed in glial cell survival counts, $\mathrm{LD}_{50}$ values obtained by the, ATP assay were markedly lower those determined by the MTS assay (Figures 2-5). At very low cell numbers, these differences in $\mathrm{LD}_{50}$ values led the ATP and MTS assays to generate conflicting results. At initial cell counts of less than 2,000 in the cases of paclitaxel and carmustine (Figures 3 and 4), and less than 1000 in the case of cisplatin (Figure 2), these drugs were generally indicated as ineffective against the glioma cultures with the MTS assay but effective against these cultures with the ATP assay. Above these cell numbers, the MTS and ATP assays were generally in agreement and indicated that cisplatin, paclitaxel and carmustine were effective against the glioma cultures tested (Figures 2-5). In the case of etoposide, the MTS and ATP assays showed no agreement as to the effectiveness of the drug against the glioma cultures tested up to the limit of the initial cell count of 4500 , used in this study (Figure 5).

\section{Discussion}

Currently, in vitro chemosensitivity testing of short term primary glioma cultures derived from brain biopsies has not been adopted for clinical use and the present study investigates whether the MTS and ATP assays, which determine drug cytotoxicity via colorimetric and lumi- nescence analysis respectively, could potentially fulfil this role.

MTS and ATP assay of the non-drug treated cell populations of glioma tissue cultures, A to $\mathrm{O}$, confirmed previous results [19]. It was found in this previous work that, in contrast to the MTS assay, across the cell number ranges studied for these cultures $(0-4500)$, the ATP assay demonstrated a strong linear response to changes in cell number, especially at cell numbers $<200$ (see [19]). The ATP assay was used in the current study to investigate the chemosensitivity of fifteen short term primary glioma cultures to a series of anticancer drugs (Figures 2-5). The drugs selected for this study have all previously been shown to be effective against glioma and included cisplatin, paclitaxel, etoposide and carmustine although their frequency of present therapeutic use varies $[8$, 22-26]. Currently, carmustine is the favoured treatment for high grade glioma patients and can be administered in the form of the 'Gliadel' wafer implant. These wafers provide an intra-tumoral supply of the drug and a modest increase in survival has been reported [27]. Cisplatin is infrequently used in the treatment of glioma due to difficulty in crossing the blood-brain-barrier. Nonetheless, studies employing intra-arterial injections of the drug, sometimes with pre-disruption of the blood-brain barrier via a mannitol bolus, have been shown to have efficacy although there are associated neuro-toxic side-effects 
[28]. Similarly, paclitaxel is an infrequent but potentially useful neuro-oncology chemotherapeutic agent. Studies have reported that patients administered with intratumoural convection-enhanced delivery of this drug demonstrated high anti-tumour response rates. However, again, use of this drug is associated with neurological complications [29]. At the present time, etoposide is not utilised in chemotherapeutic regimes.

Based on their $\mathrm{LD}_{50}$ values, it was generally found that the glioma cultures tested by the ATP assay were sensitive to cisplatin and paclitaxel but relatively resistant to etoposide and carmustine. A similar trend was observed when corresponding studies were performed using the MTS assay but the $\mathrm{LD}_{50}$ values obtained by the latter assay were markedly higher than those determined by the ATP assay (Figures 2-5), This observation suggests that chemosensitivity data obtained by the MTS assay has the potential to be misleading and is clearly demonstrated by the fact that at low cell numbers $(<2000)$, a number of glioma cultures were found to be resistant to these drugs by the latter assay but sensitive to cisplatin, paclitaxel and carmustine by the ATP assay. Indeed, glioma cultures $\mathrm{A}$ and $\mathrm{C}$ were indicated as sensitive to each of the four anticancer drugs tested by the ATP assay but showed no response to these drugs according to the MTS assay.

Taken overall, the findings presented in this study show that in terms of sensitivity, the ATP assay is superior to a colorimetric assay for chemosensitivity testing in gliomas. This clearly gives the ATP assay a major advantage over the MTS assay and taken with the fact that the former assay is simple and readily gives reproducible results, this makes the ATP highly attractive for clinical application. Moreover, it is well known that the $\mathrm{LD}_{50}$ for a drug in a chemosensitivity assay is highly dependent on the type of assay used [30]. It is therefore important that the most sensitive assay available be used, as the $\mathrm{LD}_{50}$ values from less sensitive assays may be misleading, which was clearly demonstrated in this study. In all cases, where glioma cultures were found to be sensitive to a given drug by both the ATP and MTS assays, the former assay consistently gave $\mathrm{LD}_{50}$ values, which were lower than those given by the latter assay. These observations clearly reflect a real difference in the ability to detect glioma cell death and are due to inherent variation between the two assays rather than technical error; the reagents used in this study were commercially obtained kits with good quality controls, and the plate reader employed was autocalibrated and regularly serviced.

In conclusion, the ATP assay exhibits much greater sensitivity than the MTS assay when testing primary glioma tumour cultures for chemosensitivity. A lumines- cence based assay such as the ATP assay should therefore be the assay of choice when performing chemosensitivity testing in primary tumour cultures. This is especially true for tumours such as gliomas where the yield of biopsied tissue and cultured cells is likely to be very variable.

\section{Acknowledgements}

The authors gratefully acknowledge the help and support provided by the Sidney Driscoll Neuroscience Foundation, SDNF Brain Tumour North West, the Rosemere Cancer Foundation, Preston, UK and Brain Tumour North West Tissue Bank, UK.

\section{REFERENCES}

[1] M. L. Rosenblum, "Chemosensitivity Testing for Human Brain Tumors," Progress in Clinical and Biological Research, Vol. 48, 1980, pp. 259-276.

[2] U. Bogdahn, "Chemosensitivity of Malignant Human Brain Tumors. Preliminary Results," Journal of Neurooncology, Vol. 1, No. 2, 1983, pp.149-166. doi:10.1007/BF00182961

[3] G. Nikkhah, J. C. Tonn, O. Hoffmann, H. P. Kraemer, J. L. Darling, W. Schachenmayr and R. Schonmayr "The MTT Assay for Chemosensitivity Testing of Human Tumors of the Central Nervous System. Part II: Evaluation of Patient- and Drug-Specific Variables" Journal of Neurooncology, Vol. 13 No. 1, 1992, pp. 13-24. doi:10.1007/BF00172942

[4] J. C. Tonn, W. Schachenmayr and H. P. Kraemer, "In Vitro Chemosensitivity Test of Malignant Gliomas: Clinical Relevance of Test Results Independent of Adjuvant Chemotherapy," Anticancer Research, Vol. 14, No. 3B, 1994, pp. 1371-1375.

[5] L. Mollgard, M. Prenkert, A. Smolowicz, C. Paul and U. Tidefelt, "In Vitro Chemosensitivity Testing of Selected Myeloid Cells in Acute Myeloid Leukemia," Leukemia and Lymphoma, Vol. 44, No. 5, 2003, pp. 783-789. doi:10.1080/1042819031000067594

[6] L. Mollgard, U. Tidefelt, B. Sundman-Engberg, C. Lofgren and C. Paul, "In Vitro Chemosensitivity Testing in Acute Non Lymphocytic Leukemia Using the Bioluminescence ATP Assay," Leukemia Research, Vol. 24, No. 5, 2000, pp. 445-452. doi:10.1016/S0145-2126(00)00003-5

[7] T. Hayon, A. Dvilansky, O. Shpilberg and I. Nathan, "Appraisal of the MTT-Based Assay as a Useful Tool for Predicting Drug Chemosensitivity in Leukemia," Leukemia and Lymphoma Vol. 44, No. 11, 2003, pp. 1957-1962. doi:10.1080/1042819031000116607

[8] A. Desjardins, J. N. Rich, J. A. Quinn, J. Vredenburgh, S. Gururangan, S. Sathornsumetee, D. A. Reardon, A. H. Friedman, D. D. Bigner and H. S. Friedman, "Chemotherapy and Novel Therapeutic Approaches in Malignant Gliomas," Frontiers in Bioscience, Vol. 10, 2005, pp. 2645-2668. doi:10.2741/1727 
[9] M. G. Castro, R. Cowen, I. K. Williamson, A. David, M. J. Jimenez-Dalmaroni, X. Yuan, A. Bigliari, J. C. Williams, J. Hu and P. R. Lowenstein, "Current and Future Strategies for the Treatment of Malignant Brain Tumors," Pharmacology and Therapeutics, Vol. 98, No. 1, 2003, pp. 71-108. doi:10.1016/S0163-7258(03)00014-7

[10] N. G. Avgeropoulos and T. T. Batchelor, "New Treatment Strategies for Malignant Gliomas," Oncologist, Vol. 4, No. 3, 1999, pp. 209-224.

[11] T. Mosmann, "Rapid Colorimetric Assay for Cellular Growth and Survival: Application to Proliferation and Cytotoxicity Assays," Journal of Immunological Methods, Vol. 65, No. 1-2, 1983, pp. 55-63. doi:10.1016/0022-1759(83)90303-4

[12] A. H. Cory, T. C. Owen, J. A. Barltrop and J. G. Cory, "Use of an Aqueous Soluble Tetrazolium Formazan Assay for Cell-Growth Assays in Culture," Cancer Communications, Vol. 3, No. 7, 1991, pp. 207-212.

[13] S. P. M. Crouch, R. Koslowski, K. J. Slater and J. F. Fletcher, "The Use of ATP-Bioluminescence in Cytokine Bioassays as a Measure of Cell Proliferation and Cytotoxicity," Lymphokine and Cytokine Research, Vol. 12, No. 5, 1993, pp. 397-397.

[14] A. T. O'Meara and B. U. Sevin, "Predictive Value of the ATP Chemosensitivity Assay in Epithelial Ovarian Cancer," Gynecologic Oncology, Vol. 83, No. 2, 2001, pp. 334-342. doi:10.1006/gyno.2001.6395

[15] K. Endo, Y. Maehara, T. Kusumoto, Y. Ichiyoshi, M. Kuwano and K. Sugimachi, "Expression of MultidrugResistance-Associated Protein (MRP) and Chemosensitivity in Human Gastric Cancer," International Journal of Cancer, Vol. 68, No. 3, 1996, pp. 372-377. doi:10.1002/(SICI)1097-0215(19961104)68:3<372::AIDIJC16>3.0.CO;2-A

[16] H. Kawamura, K. Ikeda, I. Takiyama and M. Terashima, "The Usefulness of the ATP Assay with Serum-Free Culture for Chemosensitivity Testing of Gastrointestinal Cancer," European Journal of Cancer, Vol. 33, No. 6, 1997, pp. 960-966. doi:10.1016/S0959-8049(97)00075-0

[17] C. M. Kurbacher, O. M. Grecu, U. Stier, T. J. Gilster, M. M. Janat, M. Untch, G. Konecny, H. W. Bruckner and I. A. Cree, "ATP Chemosensitivity Testing in Ovarian and Breast Cancer: Early Clinical Trials: Recent Results," Cancer Research, Vol. 161, 2003, pp. 221-230.

[18] S. Sharma, M. H. Neale, F. Di Nicolantonio, L. A. Knight, P. A. Whitehouse, S. J. Mercer, B. R. Higgins, A. Lamont, R. Osborne, A. C. Hindley, C. M. Kurbacher and I. A. Cree, "Outcome of ATP-Based Tumor Chemosensitivity Assay Directed Chemotherapy in Heavily PreTreated Recurrent Ovarian Carcinoma," BMC Cancer, Vol. 3, No. 19, 2003. http://www.biomedcentral.com/1471-2407/3/19

[19] T. P. Dawson, R. V. Iyer, R. W. Lea, P. Roberts, F. Harris, K. Ashton, A. Golash and C. H. G. Davis, "The MTS Versus the ATP Assay for in Vitro Chemosensitivity Testing of Primary Glioma Tissue Culture," Neuropathology and Applied Neurobiology, Vol. 36, No. 6, 2010, pp. 564-567. doi:10.1111/j.1365-2990.2010.01096.x
[20] D. E. Thurston, "Chemistry and Pharmacology of Anticancer Drugs," CRC Press, Oxford, 2006. doi:10.1201/9781420008906

[21] H. B. Newton, "Intra-Arterial Chemotherapy of Primary Brain Tumors," Current Treatment Options in Oncology, Vol. 6, No. 6, 2005, pp. 519-530. doi:10.1007/s11864-005-0030-1

[22] National Institute for Health and Clinical Excellence, "Glioma (Newly Diagnosed and High Grade) - Carmustine Implants and temozolomide: Appraisal Consultation Document," 2010.

[23] S. H. Tseng, M. S. Bobola, M. S. Berger and J. R. Silber, "Characterization of Paclitaxel (Taxol) Sensitivity in Human Glioma- and Medulloblastoma-Derived Cell Lines," Neuro-Oncology, Vol. 1, No. 2, 1999, pp. 101108.

[24] M. Zhao, C. Liang, A. M. Li, J. Chang, H. J. Wang, R. M. Yan, J. J. Zhang and J. L. Tai, "Magnetic Paclitaxel Nanoparticles Inhibit Glioma Growth and Improve the Survival of Rats Bearing Glioma Xenografts," Anticancer Research, Vol. 30, No. 6, 2010, pp. 2217-2223.

[25] M. M. Mrugala, S. Kesari, N. Ramakrishna and P. Y. Wen, "Therapy for Recurrent Malignant Glioma in Adults," Expert Review of Anticancer Therapy, Vol. 4, No. 5, 2004, pp. 759-782. doi:10.1586/14737140.4.5.759

[26] R. V. Iyer, "A Feasibility Study of Chemosensitivity Testing in Primary Cultures from Malignant Gliomas, and Analysis of Drug Resistance Mechanisms," MD, University of Central Lancashire, 2006.

[27] M. Westphal, Z. Ram, V. Riddle, D. Hilt and E. Bortey, and on Behalf of the Executive Committee of the Gliadel Study Group, "Gliadel (R) Wafer in Initial Surgery for Malignant Glioma: Long-Term Follow-up of a Multicenter Controlled Trial," Acta Neurochirurgica, Vol. 148, No. 3, 2006, pp. 269-275. doi:10.1007/s00701-005-0707-Z

[28] N. D. Doolittle, M. E. Miner, W. A. Hall, T. Siegal, E. J. Hanson, E. Osztie, L. D. McAllister, J. S. Bubalo, D. F. Kraemer, D. Fortin, R. Nixon, L. L. Muldoon and E. A. Neuwelt, "Safety and Efficacy of a Multicenter Study Using Intraarterial Chemotherapy in Conjunction with Osmotic Opening of the Blood-Brain Barrier for the Treatment of Patients with Malignant Brain Tumors," Cancer, Vol. 88, No. 3, 2000, pp. 637-647.

doi:10.1002/(SICI)1097-0142(20000201)88:3<637::AIDCNCR22>3.0.CO;2-Y

[29] Z. Lidar, Y. Mardor, T. Jonas, R. Pfeffer, M. Faibel, D. Nass, M. Hadani and Z. Ram, "Convection-Enhanced Delivery of Paclitaxel for the Treatment of Recurrent Malignant Glioma: A Phase I/II Clinical Study," Journal of Neurosurgery, Vol. 100, No. 3, 2004, pp. 472-479. doi:10.3171/jns.2004.100.3.0472

[30] W. K. Yung, J. R. Shapiro and W. R. Shapiro, "Heterogeneous Chemosensitivities of Subpopulations of Human Glioma Cells in Culture," Cancer Research, Vol. 42, No. 3, 1982, pp. 992-998. 